\title{
Survival, Dispersal, and Primary Infection Site for Cercospora beticola in Sugar Beet
}

\author{
J. Khan, L. E. del Rio, R. Nelson, V. Rivera-Varas, and G. A. Secor, Department of Plant Pathology, North Dakota \\ State University, Fargo 58105; and M. F. R. Khan, North Dakota State University and University of Minnesota
}

\begin{abstract}
Khan, J., del Rio, L. E., Nelson, R., Rivera-Varas, V., Secor, G. A., and Khan, M. F. R. 2008. Survival, dispersal, and primary infection site for Cercospora beticola in sugar beet. Plant Dis. 92:741-745.

Cercospora beticola survives as stromata in infected crop residue. Spores produced on these survival structures serve as primary inoculum during the next cropping season. This study was conducted to determine how long $C$. beticola can survive at different soil depths, the mechanism of inoculum dispersal, and the primary infection site in sugar beet. Longevity of $C$. beticola was studied over a 3-year period under field conditions at Fargo, ND. C. beticola-infected leaves were placed at depths of 0,10 , and $20 \mathrm{~cm}$ and retrieved after 10,22, and 34 months. Survival of C. beticola inoculum declined with time and soil depth. Inoculum left on the soil surface, $0 \mathrm{~cm}$ in depth, survived the longest (22 months) compared with that buried at $10 \mathrm{~cm}$ (10 months) and $20 \mathrm{~cm}$ (10 months). C. beticola dispersal from the primary source of inoculum was studied in the field for three growing seasons. Sugar beet plants were surrounded with plastic cages with and without ground cover, or exposed with and without ground cover. Significantly higher disease severity was observed on exposed plants than caged plants with or without ground cover, suggesting that wind was the major dispersal factor for $C$. beticola inoculum. The primary infection site by $C$. beticola was determined in a greenhouse study. Leaves, roots, and stems of healthy sugar beet plants were inoculated with $C$. beticola. Cercospora leaf spot symptoms were observed only on plants that were leaf inoculated, suggesting that the leaf was the primary infection site for C. beticola.
\end{abstract}

Additional keywords: Beta vulgaris, epidemiology, residue degradation

Minnesota and North Dakota cultivated $58 \%$ of the total sugar beet (Beta vulgaris L.) hectarage in the United States in 2005 and contributed to the United States being ranked as one of the top four sugarproducing countries worldwide (18). The sugar beet industry plays a pivotal role in the economy, particularly in rural areas, of Minnesota and North Dakota, where it contributed a total economic impact of over $\$ 3$ billion based on the 2003 sugar beet crop (3). One of the major factors limiting sugar beet production in this region is the fungal disease Cercospora leaf spot (CLS).

CLS, caused by Cercospora beticola Sacc., is one of the most destructive foliar diseases of sugar beet in warm, humid areas worldwide (7-9), and is responsible for significant reductions in root yield, sucrose concentration, and recoverable sugar, while increasing the concentration of impurities which result in higher processing costs $(25,28)$.

Corresponding author: M. F. R. Khan

E-mail: mohamed.khan@ndsu.edu

Accepted for publication 20 December 2007.

doi:10.1094/PDIS-92-5-0741

(C) 2008 The American Phytopathological Society
Four to five genes are responsible for conferring resistance to CLS (27). However, it is difficult to combine high levels of resistance and high recoverable sucrose yield in sugar beet cultivars (26). Commercial cultivars generally have moderate levels of resistance to CLS and require fungicide applications to produce acceptable yields (16). In Minnesota and North Dakota, CLS is managed by reducing inoculum pressure using crop rotation and tillage, using tolerant cultivars, planting no closer than $33 \mathrm{~m}$ from a field that had sugar beet the previous year, and timely fungicide applications $(10,12,34)$.

Our recommendation for CLS control has been predicated on research that showed that $C$. beticola infects only the aboveground parts of sugar beet plants (14). However, the possibility of systemic infection of leaves through root inoculation $(31,32)$ has raised concerns about current management strategies and warrants a review of such potential portals of entry. Similarly, other aspects of the epidemiology of this disease, such as survival duration of $C$. beticola in soil and the mechanism of inoculum dispersal, have not been studied under Minnesota and North Dakota conditions. Thus, the objectives of this study were to determine (i) survival duration of $C$. beticola at different depths in soil under field conditions, (ii) mechanism of inoculum dispersal, and (iii) the primary infection site in sugar beet.

\section{MATERIALS AND METHODS}

Survival of $C$. beticola inoculum under field conditions. Sugar beet leaves from susceptible cv. HH Agate (29), severely affected by CLS ( $>70 \%$ disease severity), were collected from nonsprayed fields at St. Thomas, ND, in September 2002. Leaves were dried at room temperature $\left(22 \pm 1^{\circ} \mathrm{C}\right)$ for 3 days and used for inoculum. Inoculum viability was tested on sugar beet plants at 0 months according to the inoculation bioassay mentioned below. Leaf samples of 10 leaves each were placed in nylon bags and sealed in protective fiberglass mesh sacks. The sacks were pinned with $1-\mathrm{m}$-long aluminum wire onto the soil surface $(0 \mathrm{~cm})$ or placed at depths of 10 or $20 \mathrm{~cm}$ in a silty clay soil $(50 \%$ clay, 6 to $7 \%$ organic matter, $\mathrm{pH}$ 7.2) (22) at the weather station site at North Dakota State University, Fargo, where soil temperature and precipitation were recorded. The site had been fallow for several years. Treatments were replicated three times. The experiment was repeated about $15 \mathrm{~m}$ apart at the same site simultaneously. Sacks were placed in the field in September 2002 and retrieved after 10, 22, and 34 months for the inoculum survival test. At retrieval, inoculum was removed from the sacks and air dried at $22 \pm 1^{\circ} \mathrm{C}$ for 5 days. Dried leaves were ground with a coffee grinder, placed in a sterilized disposable plastic vials, and used for inoculation the same day.

C. beticola inoculum was tested for viability on culture medium in the laboratory and on susceptible sugar beet plants in the greenhouse. In the laboratory, water-agar amended with antibiotics (20 g of agar, $0.01 \mathrm{~g}$ of streptomycin, $0.01 \mathrm{~g}$ of ampicillin, $0.001 \mathrm{~g}$ of chlorphenicol, $0.001 \mathrm{~g}$ of polymyxin B sulfate, and 1 liter of distilled water) and V8 agar medium amended with antibiotics $(200 \mathrm{ml}$ of clarified V8 juice, 3 $\mathrm{g}$ of $\mathrm{CaCo}_{3}, 0.01 \mathrm{~g}$ of ampicillin, $0.001 \mathrm{~g}$ of polymixin $\mathrm{B}$ sulfate, and $15 \mathrm{~g}$ of agar, volume adjusted to 1 liter with distilled water, $\mathrm{pH}$ 7.2) were used for the isolation of the pathogen. In the greenhouse, sugar beet cv. Beta 3800 , highly susceptible to $C$. beticola with a Kleinwanzlebener Saatzucht (KWS) rating of 4.7 (19), was grown in a peat mix (Sun Gro Horticulture Canada, Ltd.) in 12-by-12-by-15-cm plastic pots for 2 months. Slow-release fertil- 
izer (Osmocote 14:14:14; Scotts-Sierra Horticultural Products Company, Marysville, $\mathrm{OH}$ ) was incorporated into the potting medium before planting at a rate of $17.5 \mathrm{~g} /$ liter of medium to supply adequate nutrients. Just before inoculation, sugar beet plants were watered to about medium saturation and sprinkled for leaf wetness. Each sugar beet plant was inoculated by sprinkling $0.5 \mathrm{~g}$ of the retrieved C. beticola inoculum directly on the leaves. Inoculated plants then were covered with transparent plastic bags for $48 \mathrm{~h}$ to maintain high relative humidity $(\mathrm{RH}) \quad(\geq 90 \%)$ conditions favorable for pathogen infection. The inoculated plants were arranged in a randomized complete block design and incubated in a greenhouse for 21 days at $25 \pm 2{ }^{\circ} \mathrm{C}$ under a combination of daylight and supplemental lighting $\left(225 \mu \mathrm{E} \mathrm{m}^{-2} \mathrm{~s}^{-1} ; 16 \mathrm{~h}\right.$ per day). Each treatment consisted of three plants and was replicated three times. Plants were watered as needed. At 21 days after inoculation, the number of leaf spots produced by $C$. beticola on each plant was counted as an expression of the pathogen viability. The pathogen was reisolated from the leaf spots on V8 agar medium to confirm that it was $C$. beticola. The viability test was conducted on the inoculum buried at two different spots at the same site as two separate trials to confirm the results.

Inoculum viability data from the two experiments were pooled after Bartlett's test for homogeneity of variance indicated that variances were not statistically different from each other. Analysis of variance (ANOVA) was conducted using SAS (version 9.0; Statistical Analysis System, Cary, NC) to determine the viability of $C$. beticola inoculum with time and depth in soil. Least significance difference (LSD) at $P=$ 0.05 was calculated to compare differences in average number of leaf spots per plant produced by the inoculum buried at different depths over time. Simple linear regression analysis was performed to predict inoculum viability (expressed as number of foliar lesions) with time at different depths using the mathematical equation $Y^{*}$ $=a+b X$, in which $Y^{*}=$ predicted number of leaf lesions, $a=$ number of lesions produced at the beginning of the experiment (or viability calculated at time zero), and $b$ $=$ rate of viability decline at time $X$.

Mechanism of inoculum dispersal. This study was conducted during the sugar beet growing seasons in 2002, 2003, and 2004 at Breckenridge, MN. Corn, wheat, and soybean were used in a 3-year rotation with sugar beet at the research sites. Sugar beet cv. Beta 3800 was planted in the first week of May each year. Seed were planted into rows $0.55 \mathrm{~m}$ wide and $9.0 \mathrm{~m}$ long. Terbufos (Counter 15G; BASF, Raleigh, NC) was applied in-furrow at planting at a rate of $3.7 \mathrm{~kg}$ a.i ha ${ }^{-1}$ to control sugar beet root maggot (Tetanops myopaeformis Von Röder). Weeds were controlled using rec- ommended herbicides (10), cultivation, and hand weeding. At the four-leaf stage, populations were thinned to 86,450 plants $\mathrm{ha}^{-1}$. Because CLS symptoms usually are observed after row closure, typically in July, treatments were set up in the first week of June. Treatments were (i) plastic cage around sugar beet plants, (ii) plastic cage around sugar beet plants and ground covered with plastic, (iii) sugar beet plants exposed (not surrounded by cage) but ground covered with plastic, and (iv) untreated control (no cage and no ground cover). Plastic cage treatments comprised four cages with 20 plants per cage. The cages had a cubic form and consisted of a steel frame ( 2 by 2 by $2 \mathrm{~m}$ ) that had open tops and bottoms and a plastic sheet covering the remaining four sides. Ground was covered with black plastic carefully laid down between rows of sugar beet plants to prevent splash dispersal of any inoculum present in the soil. Treatments with exposed plants comprised six rows $0.55 \mathrm{~m}$ wide and $9.0 \mathrm{~m}$ long. Treatments were arranged in a randomized complete block design with three replicates. CLS developed from naturally occurring inoculum. Disease severity data were collected in September on the middle two rows of exposed plants and on all caged plants using the KWS scale (11). The KWS scale ranges from 1 to 9 , in which $1=$ no CLS symptoms, $3=$ leaf spots on older leaves, 5 $=$ leaf spots coalescence to form small necrotic areas, $7=$ death of older leaves and leaf spot progression to the inner leaves, and $9=$ death of all leaves and initiation of new foliage. Identity of $C$. beticola was confirmed in the laboratory.

ANOVA to determine the effects of the various treatments on CLS severity was performed using SAS (version 9.0; (Statistical Analysis System). LSD at $P=0.05$ was calculated to compare differences in mean disease severity among treatments.

Primary infection site of $\boldsymbol{C}$. beticola in sugar beet. The experiment was conducted in the greenhouse at the Department of Plant Pathology, North Dakota State University, Fargo. Sugar beet cv. Beta 3800 was planted in 9-by-9-by-7-cm plastic pots containing peat mix amended with slow-release fertilizer (Osmocote 14:14:14) as described above. Pots were thinned at two-leaf stage to one plant per pot. C. beticola isolate 04-138, collected from a sugar beet field in Minnesota in 2004 (provided by G. Secor, Department of Plant Pathology, North Dakota State University, Fargo), was used for inoculations. Inoculum was prepared by growing C. beticola on clarified V8 agar medium for 7 days under fluorescent light at $22 \pm$ $1{ }^{\circ} \mathrm{C}$ to induce conidial production. Conidia were harvested by flooding the culture plates with sterile, distilled water containing two droplets of Tween 20 (SigmaAldrich, St. Louis) per $100 \mathrm{ml}$ and pouring the conidial suspension into a flask. Conid- ial concentration was determined with a hemacytometer and adjusted to 25,000 spores $/ \mathrm{ml}$ for maximum leaf spot production (33). Twenty-one-day-old plants were inoculated with $C$. beticola. Treatments included leaf inoculation, root inoculation by drenching the potting medium, bareroot inoculation, stem inoculation, and uninoculated control. Leaves were inoculated using an airbrush to spray the conidial suspension on the leaves until runoff. Roots of plants in pots were inoculated by using a disposable syringe to drench the potting medium with $5 \mathrm{ml}$ of conidial suspension $1 \mathrm{~cm}$ away from the stem. Bareroot inoculation was achieved by carefully removing the potting medium from roots, rinsing roots with tap water, and passing roots through a hole made in the bottom of a 250-ml Styrofoam pot. The roots of each plant were immersed in the conidial suspension for $48 \mathrm{~h}$. Plants were handled carefully so that the upper parts of the plant did not make contact with the suspension. For stem inoculation (4), C. beticola was grown for 7 days on V8 agar medium. The colonized area of the plate was removed with a sterilized knife, placed in a hypodermic syringe, and made into slurry by passing into another syringe two times. An incision was made in the stem of individual sugar beet plants and approximately 0.2 to $0.4 \mathrm{ml}$ of the slurried inoculum was injected into the wound with a syringe. The injected site was covered with wet cotton and wrapped with aluminum foil to retain moisture. Control plants were sprayed with distilled water, drenched with distilled water, or injected with V8 agar medium. The surface of pots containing root-inoculated plants was covered with light-weight foam boards to prevent any soil particles from reaching aboveground plant parts. Inoculated and control plants were kept in a moist chamber for $48 \mathrm{~h}$ at $24 \pm 1^{\circ} \mathrm{C}$ and $100 \% \mathrm{RH}$ to facilitate infection, then transferred to the greenhouse ( 25 $\pm 2{ }^{\circ} \mathrm{C}$ and $225 \mu \mathrm{E} \mathrm{m}^{-2} \mathrm{~s}^{-1}$; 16 -h photoperiod) equipped with a fogger to maintain $\geq 90 \%$ RH. A randomized complete block design was used. Each treatment comprised four plants with five replicates. Plants were evaluated for disease symptoms through 35 days in the greenhouse $(31,32)$. The identity of the pathogen was verified by plating of infected tissues on V8 agar medium followed by verification with light microscopy. The experiment was repeated twice.

\section{RESULTS}

Survival of $C$. beticola inoculum under field conditions. In the laboratory, it was not possible to isolate the pathogen directly from the disintegrated plant tissues. However, in the greenhouse, C. beticola from fresh and buried viable inoculum caused typical symptoms of circular lesions which enlarged to 2 to $5 \mathrm{~mm}$ and appeared light tan to gray with brown to 
reddish-purple margins on sugar beet leaves after inoculation.

Duration and depth of placement negatively impacted the survival of $C$. beticola inoculum on sugar beet leaves (Table 1). Before placement of the inoculum, the average number of spots produced was 32 per plant. After 10 months' placement at depths of 0,10 , and $20 \mathrm{~cm}$, inoculum viability was reduced by 59,74 , and $76 \%$, respectively. Similarly, after 10 months, viability of inoculum at $0 \mathrm{~cm}$ was, on average, $40 \%$ higher than the inoculum at 10 and $20-\mathrm{cm}$ depths. There was no significant difference between the number of leaf spots produced by inoculum buried at 10 and $20-\mathrm{cm}$ depths. After 22 months, viability of $C$. beticola inoculum was very low (33\%) on residues left on the soil surface; and inoculum at depths of 10 and $20 \mathrm{~cm}$ did not survive. After 34 months, the inoculum placed at all depths was fully decomposed, with no remnants in the nylon bags, and viability testing was not possible.

Residue placed at 10- and 20-cm depths degraded faster than the residue left on the soil surface. Regression analysis $\left(r^{2}=\right.$ $0.89, P=0.05)$ showed that viability of $C$. beticola inoculum declined at a rate of $2.75 \%$ for each month that inoculum was left on the soil surface (Fig. 1); however, when inoculum was placed $10 \mathrm{~cm}$ in the soil, its viability declined at a rate of 1.6 times faster.

Mechanism of inoculum dispersal. CLS severity was higher in 2003 and 2004 compared with 2002. However, mean disease severity in the caged plants with and without ground cover was significantly lower than in the exposed plants with and without ground cover during all years of the study (Table 2). Covering the ground with plastic did not have a significant $(P=$ 0.05 ) impact on disease severity independently of the plants being caged or not.

Primary infection site of $\boldsymbol{C}$. beticola in sugar beet. Only leaf-inoculated sugar beet plants showed symptoms of CLS. Foliar symptoms were observed within 10 days from inoculation and reached a maximum of 58 lesions per plant 21 days after inoculation. Root inoculations, either by soil drenching or bare-root dipping in conidial suspension, resulted in no symptoms of the disease on the aboveground plant parts. Injection of the inoculum into the stem did not produce any symptoms on leaves or other aboveground plant parts.

\section{DISCUSSION}

In the laboratory, it was not possible to isolate $C$. beticola directly from the leaves on the culture medium because of the slow-growing nature of the pathogen and unavailability of a selective medium. Thus, appraisal of inoculum viability was based entirely on the number of foliar lesions resulting from inoculating a very susceptible sugar beet cultivar with infected tissues.
Survival of $C$. beticola inoculum was significantly impacted by both depth and duration of placement. A higher rate of inoculum survival occurred on the soil surface compared with inoculum placed at depths of 10 and $20 \mathrm{~cm}$, with the pathogen surviving after 22 months on the surface but only after 10 months when placed at depths of 10 and $20 \mathrm{~cm}$. No viable inoculum propagules were present after 34 months' placement at all depths. This study showed that $C$. beticola survives much longer than the 8 months for dried herbarium material reported by Pool and McKay (21). Nagel (17) showed that C. beticola survived in naturally infested soil for 20

Table 1. Severity of Cercospora beticola expressed as number of leaf spots produced by inoculum buried at different depths and for different periods of time under field conditions ${ }^{\mathrm{a}}$

\begin{tabular}{lcccc}
\hline & \multicolumn{3}{c}{ Depth of burial $(\mathbf{c m})^{\mathbf{b}}$} & \\
\cline { 2 - 4 } Duration of burial (months) & $\mathbf{0}$ & $\mathbf{1 0}$ & $\mathbf{2 0}$ & LSD $(\boldsymbol{P}=\mathbf{0 . 0 5})$ \\
\hline 0 & 32.3 & 32.3 & 32.3 & NS \\
10 & 13.3 & 8.3 & 7.7 & 3.4 \\
22 & 7.3 & 0.0 & 0.0 & 2.3 \\
34 & 0.0 & - & - & - \\
LSD $(P=0.05)$ & 3.2 & 3.5 & 3.8 & $\ldots$ \\
\hline
\end{tabular}

${ }^{a}$ Disease severity measured 21 days after inoculation. LSD $=$ least significant difference at $P=0.05$; $\mathrm{NS}=$ not significant.

${ }^{\mathrm{b}}$ Each value represents the mean of 18 observations; - = data not collected because the buried inoculum was completely disintegrated and diminished when observed after 34 months.

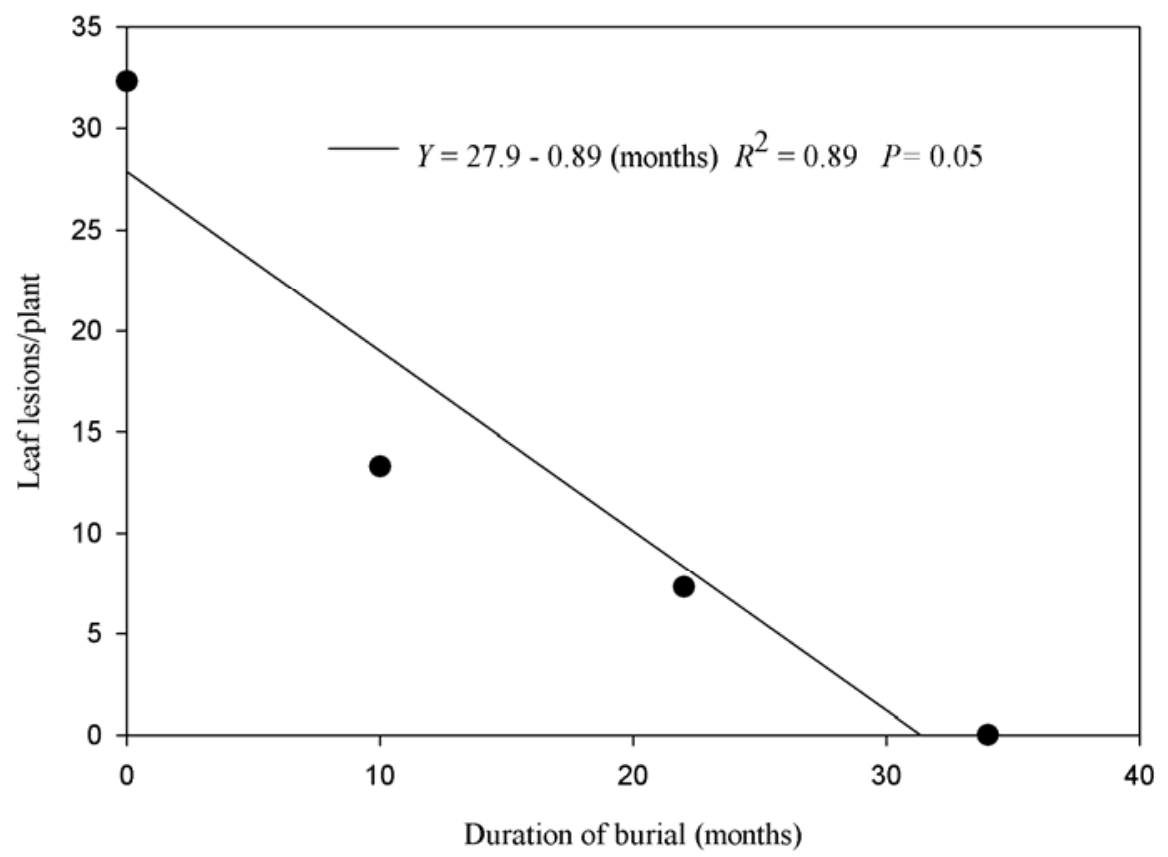

Fig. 1. Effect of time on viability of Cercospora beticola inoculum left on soil surface $(0 \mathrm{~cm}$ burial in soil) under field conditions, expressed as number of leaf spots per plant. Each data point represents the average of 18 observations.

Table 2. Cercospora leaf spot (CLS) severity on sugar beet plants caused by natural inoculation of Cercospora beticola inoculum under field conditions ${ }^{\mathrm{a}}$

\begin{tabular}{lccc}
\hline & \multicolumn{3}{c}{ Sugar beet growing seasons ${ }^{\mathbf{b}}$} \\
\cline { 2 - 4 } Treatments & $\mathbf{2 0 0 2}$ & $\mathbf{2 0 0 3}$ & $\mathbf{2 0 0 4}$ \\
\hline Nontreated control & 3.5 & 6.8 & 6.8 \\
Plants exposed and ground covered with plastic & 3.7 & 6.3 & 6.5 \\
Plastic cage around plants and ground covered with plastic & 2.2 & 3.5 & 2.4 \\
Plastic cage around plants & 2.1 & 3.7 & 2.3 \\
LSD $(P=0.05)$ & 1.0 & 0.8 & 0.6 \\
\hline
\end{tabular}

${ }^{a}$ CLS severity data were collected in September using the Kleinwanzlebener Saatzucht disease severity rating scale from 1 to 9 , in which $1=$ no CLS symptoms, $3=$ leaf spots on older leaves, $5=$ leaf spots coalescence to form small necrotic areas, $7=$ death of older leaves and leaf spot progression to the inner leaves, and $9=$ death of all leaves and initiation of new foliage. LSD $=$ protected least significant difference at $P=0.05$.

${ }^{\mathrm{b}}$ Each value represents the mean of three observations. 
months. Inoculation, initially of cotyledons and later of leaves, was achieved by sowing seed directly in flats with infested soil. In our research, materials were placed in field conditions until retrieval for inoculation whereas, in Nagel's study, flats of infested soils either were covered and left outside during the winter for 3 months or kept at low temperatures $\left(5\right.$ to $\left.-7^{\circ} \mathrm{C}\right)$ indoors for 9 months. Because the flats were not exposed to rainfall, it is possible that reduced moisture could have contributed to longer survival of the pathogen in the flats. Nagel's study also showed that the quantity of $C$. beticola in soil was significantly reduced over time. In our study, as well as in others from different research groups (17,31), fast-growing microorganisms quickly covered the petri dishes plated with infected leaves and retrieved inoculum. The negative impact of burying infected plant materials on survival of pathogens also has been shown by other researchers working on fungi traditionally considered to be soilborne, such as Rhizoctonia solani (1) and Macrophomina phaseolina (2).

Survival of $C$. beticola inoculum for a shorter period of time when placed in the soil compared with when left on the soil surface also may be attributed to consistently longer periods of higher soil moisture and soil temperature and increased microbial activity in the soil, which facilitate accelerated degradation of crop residues. Pryor et al. (23) reported that high soil moisture reduced survival of Alternaria dauci (J. G. Kühn) J. W. Groves \& Skolko in carrot (Daucus carota L.) crop residue. Though a chemical test or a dry matter measurement for residue degradation was not conducted in our study, the residue from depths of 10 and $20 \mathrm{~cm}$ showed more degradation than the inoculum left on the soil surface. As such, crop residues infected with $C$. beticola and left on the soil surface may provide a substrate for the pathogen for a longer period of time than buried residue. Pereyra et al. (20) demonstrated the relationship between survival of Gibberella zeae (Schwein.) Petch and the rate of wheat (Triticum aestivum L.) residue decomposition at different depths. They showed that crop residues buried in the soil decomposed faster than residues left on the soil surface during summer compared with winter months because of warm, wet soil conditions. As such, soil temperature also may contribute to enhance decomposition of sugar beet crop residue buried in soil. Baird et al. (2) showed that cellulose-degrading fungi such as Trichoderma spp. and some species of basidiomycetes occurred in crop residue at greater frequency with increased depth than the surface crop residue.

Disease pressure was not uniform across years at the locations used to study the mechanism of inoculum dispersal; disease severity was lower in 2002 compared with 2003 and 2004. The lower disease severity probably was a result of low inoculum pressure and unfavorable environmental conditions that prevailed in the summer of 2002, because another noninoculated $C$. beticola study done by Richards and Khan (24) in the same area at the same time showed that the untreated check had a similarly low (3.8) leaf spot rating. Covering the ground with plastic, whether inside or outside of a cage, did not influence the severity of the disease indicating that, in this study, the soil supporting the sugar beet plants was not a significant source of inoculum. This would be expected because the fields on which the trials were conducted had not been planted with sugar beet in the previous 48 months. The purpose of the plastic cages was to reduce exposure of plants to wind. The fact that caged plants had significantly lower disease severity than exposed plants suggests that $C$. beticola inoculum is dispersed mainly by wind. These results are in agreement with observations made by other researchers (13-15).

In our research to determine the primary infection site for $C$. beticola, CLS symptoms were observed mainly on leaves and infrequently on petioles, due to inoculum runoff from the inoculated leaves. We could not reconcile our results with those of Vereijssen et al. $(31,32)$, who reported that the sugar beet root was another possible site of infection for $C$. beticola. In our research, no leaf infection or lesions on the stem base occurred through the stem and root inoculations, probably because the pathogen was unable to penetrate the root or establish itself in the stem to systemically or epiphytically infect the leaves. Foliar pathogens, such as Peronospora viciae f. sp. fabae on faba bean and Plasmopara halstedii on sunflower (6), have demonstrated root infection (30). These pathogens germinate at the root surface, enter the root, and colonize the plant. Consequently, although our research showed that $C$. beticola did not infect through root inoculation, practices that will result in faster decomposition of inoculum will further reduce the possibility of infection through roots.

Giannopolitis (5) reported that light is necessary after inoculation by $C$. beticola on sugar beet crowns for the appearance of symptoms on the crown. If light is indeed a requisite factor for infection after inoculation, it would suggest that root infection by $C$. beticola in the soil, in the absence of light, will not be possible. However, it may be possible for viable inoculum present in the soil to be brought to the surface through cultivation practices; such exposed inoculum may then serve to infect susceptible plants. As such, it may be useful to incorporate infected debris in soil soon after harvest to reduce viability of the inoculum and the availability of infective inoculum that can be dispersed by wind onto susceptible plants.
ACKNOWLEDGMENTS

We thank the North Dakota State Board of Agricultural Research and Education, Sugar Beet Research and Education Board of Minnesota and North Dakota for providing funding and support for this research; and C. Tandeski for laboratory assistance.

\section{LITERATURE CITED}

1. Baird, R. E., Bell, D. K., Sumner, D. K., Mullinix, B. G., and Culbreath, A. K. 1993. Survival of Rhizoctonia solani AG-4 in residual peanut shells in soil. Plant Dis. 77:973975.

2. Baird, R. E., Watson, C. E., and Scruggs, M. 2003. Relative longevity of Macrophomina phaseolina and associated mycobiota on residual soybean roots in soil. Plant Dis. 87:563 566.

3. Bangsund, D. A., and Leistritz, F. L. 2004 Economic contribution of the sugarbeet industry in Minnesota, North Dakota and Montana Agribusiness and Applied Economics Report No. 532. North Dakota State University, Fargo.

4. Dorrance, A. E., and Schmitthenner, A. F. 2000. New sources of resistance to Phytophthora sojae in the soybean plant introductions. Plant Dis. 84:1303-1308.

5. Giannopolitis, C. N. 1978. Lesions on sugarbeet roots caused by Cercospora beticola. Plant Dis. Rep. 62:424-427.

6. Gunawardena, U., and Hawes, M. C. 2002. Tissue specific localization of root infection by fungal pathogens: role of root border cells Mol. Plant-Microbe Interact. 15:1128-1136.

7. Holtschulte, B. 2000. Cercospora beticolaworldwide distribution and incidence. Pages 516 in: Cercospora beticola Sacc. Biology, Agronomic Influence and Control Measures in Sugar Beet 2000, Vol. 2. Advances in Sugar Beet Research. M. J. C Asher, B. Holtschulte, M. Richard Molard, F. Rosso, G. Steinrucken, and R. Beckers, eds. International Institute for Beet Research, Brussels.

8. Karaoglanidis, G. S., Thanassoulopoulos, C. C., and Ioannidis, P. M. 2001. Fitness of Cercospora beticola field isolates resistant and sensitive to demethylation inhibitor fungicides. Eur. J. Plant Pathol. 107:337-347.

9. Kerr, E. D., and Weiss, A. 1990. Fungicide efficacy and yield responses to fungicide treatments based on predictions of Cercospora leaf spot of sugar beet. J. Sugar Beet Res. 27:58-71.

10. Khan, M., ed. 2002. Pages 21-49 in: Sugarbeet Production Guide. North Dakota State University and University of Minnesota Extension Services.

11. Kleinwanzleber Saatzucht Ag. Einbeck. 1970. Cercospora. Kleinwanzleber Saatzucht Ag. Einbeck Rabbethge and Geisecke.

12. Lamey, H. A., Bugbee, W. M., Cattanach, A. W., and Windels, C. E. 1996. Cercospora leafspot of sugarbeet. N. D. State Univ. Ext. Circ. PP-764 (revised).

13. Lawrence, J. S., and Meredith, D. S. 1970. Wind dispersal of Cercospora beticola. Phytopathology 60:1076-1078.

14. McKay, M. B., and Pool, V. W. 1918. Field studies of Cercospora beticola. Phytopathology 8:119-136.

15. Meredith, D. S. 1967. Conidium release and dispersal in Cercospora beticola. Phytopathology 57:889-893.

16. Miller, S. S., Rekoske, M., and Quinn, A. 1994. Genetic resistance, fungicide protection and variety approval politics for controlling yield losses from Cercospora leaf spot infection. J. Sugar Beet Res. 31:7-12.

17. Nagel, C. M. 1938. The longevity of Cercospora beticola. Phytopathology 28:342-350.

18. National Agriculture Statistics Service. 2007 U.S. Dep. Agric. Nat. Agric. Stat. Serv. Online.

19. Niehaus, W. S. 2002. Results of American 
Crystal's 2001 official coded variety trials. 2001 Sugarbeet Res. Ext. Rep. N. D. State Univ. Fargo 32:333-372.

20. Pereyra, S. A., Dill-Macky, R., and Sims, A. L. 2004. Survival and inoculum production of Gibberella zeae in wheat residue. Plant Dis. 88:724-730.

21. Pool, V. W., and McKay, M. B. 1916. Climatic conditions as related to Cercospora beticola. J. Agric. Res. 6:21-60.

22. Prochnow, N. D., Lunde, N. J., Terry, W. J., and Opdahl, D. P. 1983. Soil Survey of Cass County Area, North Dakota. U. S. Govt. Printing Office, Washington, DC.

23. Pryor, B. M., Strandberg, J. O., Davis, R. M., Nunez, J. J., and Gilbertson, R. L. 2002. Survival and persistence of Alternaria dauci in carrot cropping systems. Plant Dis. 86:11151122.

24. Richards, G., and Khan, M. 2003. Effect of headline plus adjuvants on Cercospora leaf spot control and yield and quality of sugarbeet. 2002 Sugarbeet Res. Ext. Rep. N. D. State Univ. Fargo 33:220-222.

25. Shane, W. W., and Teng, P. S. 1992. Impact of Cercospora leaf spot on root weight, sugar yield and purity. Plant Dis. 76:812-820.

26. Smith, G. A., and Campbell, L. G. 1996. Association between resistance to Cercospora and yield in commercial sugarbeet. Plant Breed. 115:28-32.

27. Smith, G. A., and Gaskill, J. O. 1970. Inheritance of resistance to Cercospora leaf spot in sugarbeet. J. Sugar Beet Res. 16:172-180.

28. Smith, G. A., and Ruppel, E. G. 1973. Association of Cercospora leaf spot, gross sugar, percentage sucrose and root weight in sugarbeet. Can. J. Plant Sci. 53:695-696.

29. Steen, R. A. 2000. Results of American Crystal's 2001 official coded variety trials. 2001 Sugarbeet Res. Ext. Rep. N. D. State Univ. Fargo 32:293-335.
30. van der Gaag, D. J., and Frinking, H. D. 1997. Survival characteristics of oospore populations of Peronospora viciae f. sp. pisi in soil. Plant Pathol. 46:978-988.

31. Vereijssen, J., Schneider, J. H. M., and Termorshuizen, A. A. J. 2004. Possible root infection of Cercospora beticola in sugar beet. Eur. J. Plant Pathol. 110:103-106.

32. Vereijssen, J., Schneider, J. H. M., and Termorshuizen, A. A. J. 2005. Root infection of sugar beet by Cercospora beticola in a climate chamber and in the field. Eur. J. Plant Pathol. 112:201-210.

33. Wallin, J. R., and Loonan, D. V. 1971. Effect of leaf wetness duration and air temperature on Cercospora beticola infection of sugar beet. Phytopathology 61:546-549.

34. Windels, C. E., Bradley, C. A., and Khan, M F. R. 2003. Comparison of Cercospora and bacterial leaf spots on sugarbeet. N. D. State Univ. Univ. Minn. Ext. Circ. PP-1244. 